Dermatobia hominis, measuring $11 \mathrm{~mm}$ long $\times 4$ mm diameter.

\section{Discussion}

The human bot fly, Dermatobia hominis (also known as torsalo, berne, or nuche), is a member of the Cuterebridae, a family of the New World flies, which are usually parasites of rodents, rabbits, and hares. ${ }^{2}$ It is particularly common in the lowland forest areas of Central and Southern America, although it has been recorded at 3000 feet. The female fly, resembling a bluebottle, deposits packets of eggs on mosquitoes and other flies including Sarcophagus, Musca, or ticks, Amblyomma. These eggs are deposited on the skin, particularly the face and shoulders in humans. The warmth induces the larva to hatch from the egg, and within five or ten minutes the larva burrows into the subcutaneous tissues. The larva has a distinctive shape, with attenuation of the posterior end, which may be exposed through a hole in the skin. As the proximal part of the larva is much larger than the breathing hole, direct extraction is very difficult. This attenuation is most marked in the second stage. Development in the tissues takes from six to 12 weeks, after which the larva emerges, drops to the ground, and pupates. The adult fly emerges in three to four weeks.

The recommended treatment described by Brewer et al starves the larva of oxygen and allows extraction when it emerges. This technique failed in our hands, and our concerns about the facial nerve led us to formal exploration. Use of ultrasound to localise and size such larvae has not previously been reported and we would recommend it as an aid to management of these unusual infestations.

We thank Dr Harvey Dexter for performing the ultrasound.

1 Brewer TF, Wilson ME, Gonzalez E, Felsenstein D. Bacon therapy and furuncular myiasis. JAMA 1993;270:2087-8. Snow MH, Colbridge MJ, Edwards SK. Some unwelcome holiday souvenirs. Hospital Update 1996;22(2).

\title{
Tropical myiasis: an unwanted holiday souvenir
}

\author{
John Kitching
}

\author{
Abstract \\ A case of tropical myiasis is described and \\ its treatment outlined. \\ (F Accid Emerg Med 1997;14:178-179)
}

Keywords: tropical myiasis; treatment

A 24 year old female marine biologist who had recently returned from Belize presented to the Southampton Accident and Emergency Department with an itchy, unsightly lesion on her left upper arm. It had been present for three weeks and had been slowly growing. She was convinced that she could feel movement within the lesion and was concerned that there might be a parasitic larva present (known locally in Belize as beef flies).

Examination of her left upper arm revealed an erythematous raised lesion, $5 \mathrm{~cm}$ in diameter, with a central aperture. On closer examination, movement could be seen within the aperture. A diagnosis of tropical myiasis was made.

\section{Accident and}

Emergency

Department, Queen

Alexandra Hospital,

Cosham, Portsmouth

PO6 3LY

J Kitching

Correspondence to: Dr J Kitching.

Accepted for publication 12 November 1997

\section{Discussion}

Myiasis is the infestation of living animals by the larvae of flies. ${ }^{1-3}$ The two major species affecting man are the New World bot fly (or beef fly) (Dermatobia hominis) and the Afrotropical tumbu fly (Cardylobia anthropophagia).

The bot fly adult is rarely seen. The female lays her eggs on biting arthropods, such as mosquitoes, and the eggs hatch when in

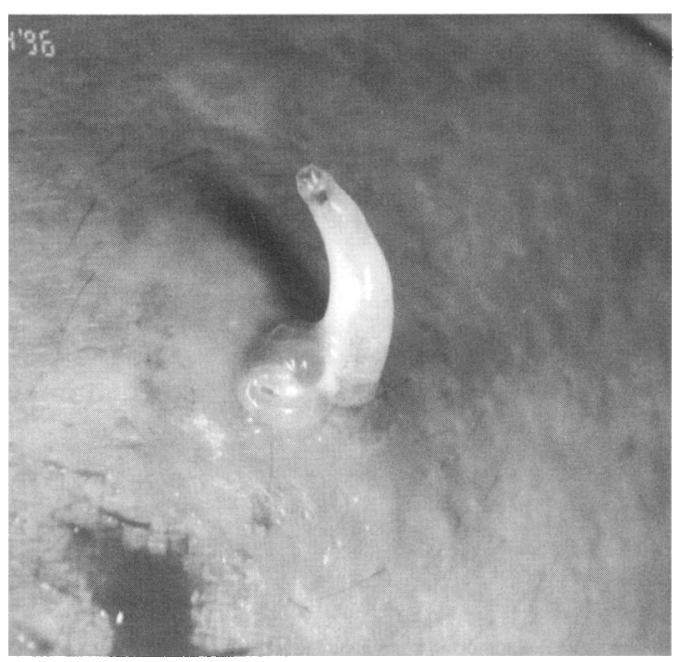

Figure 1 Bot fly larva emerging.

contact with a warm blooded animal. The larval stage lasts about 10 weeks and is marked clinically by a steadily enlarging boil with a central aperture, through which the larva respires. The larva grows up to $1 \mathrm{~cm}$ in length and is covered in ridges of spines which may cause pain on movement. If left alone, the larva will pupate and eventually emerge as an adult fly.

\section{TREATMENT}

If the central aperture is large, the larva can be removed by infiltrating local anaesthetic around its burrow, which forces it to the 
surface (fig 1). It can then be easily removed with forceps. Alternatively, a formal incision and removal can be done. It is important that all of the larva is removed, as otherwise a local granulomatous reaction can occur.

Simple dressings and antibiotic and tetanus prophylaxis are recommended.
Steffen E. Health risks in short term travellers. In: Travel medicine. Berlin: Springer Verlag, 1989:27-36.

2 Tsuda S, Nagaji J, Kurose K, Miyasotol M, Sasai Y, Yoneda Y. Furuncular cutaneous myiasis caused by Dermatobia hominis larvae following travel to Brazil. Int J Dermatol 1996;35:121-3.

3 Hall M, Wall R. Myiasis of humans and domestic animals. Adv Parasitol 1995;35:257-334.

\title{
Dermatobia hominis in the accident and emergency department: "I've got you under my skin"
}

\author{
A MacNamara, S Durham
}

\begin{abstract}
An unusual form of larval infestation from South America is presented which, in view of increasing tourism to South America's tropical areas, may present to any accident and emergency department. Infestation with Dermatobia hominis is reviewed in terms of clinical recognition and life cycle. Techniques of removal are described. (F Accid Emerg Med 1997;14:179-180)
\end{abstract}

Keywords: Dermatobia hominis infection; treatment

\section{Case history}

Two adults presented to the accident and emergency (A\&E) department of the Leicester Royal Infirmary, having recently returned from a trip to Argentina. Each complained of a single persistently discharging lesion which had been present for several weeks and which had started while they were in Argentina on holiday. In one case the lesion was on the arm and in the other case on the back. They both reported a continuous discharge from the lesions, and that they were not healing. They further reported an alarming sensation of movement within the lesion and occasionally seeing something protrude from the central pore. Physical examination revealed a lesion with raised edges, a central punctum, and surrounding erythema. A serous discharge was noted. A small tube-like structure was noted to protrude intermittently from the central pore.

Discussion with a parasitologist identified the lesions as infestation with Dermatobia hominis. The structure protruding from the lesions was the "respiratory" tube of these air breathing larvae.

\section{Emergency}

Department, Leicester

Royal Infirmary NHS

Trust, Infirmary

Square, Leicester LE1

5WW

A MacNamara

S Durham

Correspondence to:

Mr A MacNamara,

Senior Registrar in A\&E.

Accepted for publication 12 November 1996

\section{The beast}

Dermatobia hominis (human bot fly) is widely distributed throughout Central and South America, attacking a wide range of hosts from poultry through livestock, to man. The species is remarkable for the unique manner in which it delivers its eggs to a new host, by using other insects as carriers or porters. The adult female fly catches and firmly holds another insect,

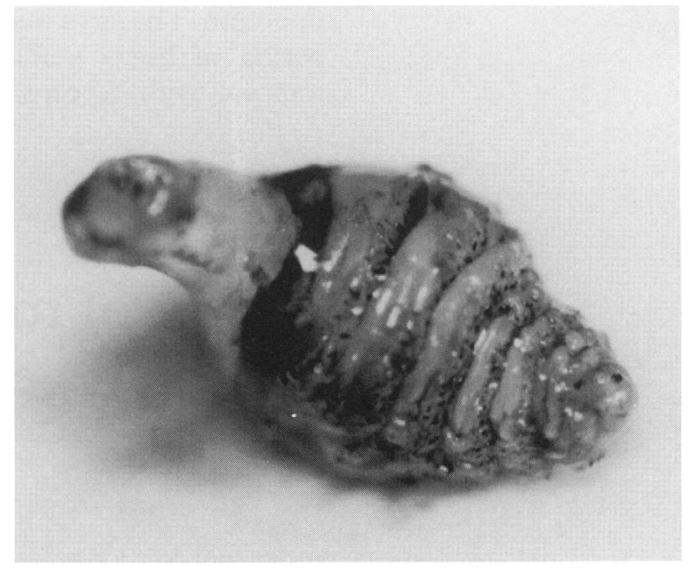

Figure 1 Intact complete larva following removal.

usually a mosquito, and attaches between six and 30 eggs to its abdomen. The larva is very sensitive to temperature changes and remains in the egg shell until it senses proximity to a warm blooded host, whereupon it rapidly hatches and penetrates the host's skin. Each larva penetrates individually, and a small nodule develops around it with a central pore through which the larva breathes. ${ }^{1}$

LIFE CYCLE

The first instar is subcylindrical with circlets of small spines. The second stage is pyriform, with stronger stout spines on the globular portion and no spines on the narrow posterior part, which acts like a respiratory siphon. During larval life the wound continually oozes serous fluid or pus, but bacteriostatic activity in the gut of the larva seems to prevent undesirable overgrowth of pyogenic bacteria. The larval stage lasts from six to 12 weeks, with the larva feeding on tissue exudate. The mature larva (third instar) leaves the host and burrows into soil to pupate, emerging after four to 11 weeks. The larvae we removed were close to reaching this stage (figure 1 ). The adults live eight to nine days, never feed, and are sexually mature three hours after emergence. 